ORIGINAL ARTICLE

\title{
The relationship between self-control and temperament: a contribution to the self-control definition debate
}

\author{
Edward Nęcka $a^{A, D, E}$, Klaudia Korona-Golec ${ }^{E}$, Teresa Hlawacz ${ }^{C, D}$, Michat Nowak ${ }^{B, C, D}$, \\ Aleksandra Gruszka-Gosiewska ${ }^{C, D}$ \\ Institute of Psychology, Jagiellonian University in Krakow, Poland
}

\section{BACKGROUND}

Self-control, as one of the most popular research topics, requires strong definition boundaries to enable generalization of the results. There are inconsistencies between researchers in the understanding of the concept, due to the fact that self-control is a complex phenomenon that involves many psychological functions and has a strong impact on human everyday performance. This research contributes to a wider scientific debate on self-control's theoretical framework by examining its relationship with Jan Strelau's theory of temperament.

\section{PARTICIPANTS AND PROCEDURE}

One hundred sixty-four adults (95 women) were asked to fill in two paper-and-pencil questionnaires: NAS-50, measuring self-control and its five factors (goal maintenance, proactive control, initiative and persistence, inhibition and adjournment, switching and flexibility), and FCB-TI, measuring six dimensions of temperament (briskness, perseverance, sensory sensitivity, emotional reactivity, endurance, and activity).
RESULTS

Three FCB-TI subscales - briskness, sensory sensitivity, and low level of emotional reactivity -were found to explain $35 \%$ of NAS-50 overall score variance. Activity showed a correlation only with the switching and flexibility subscale of NAS-50. Proactive control showed no correlation with FCB-TI scales at all.

\section{CONCLUSIONS}

Self-control and temperament are linked, although the shared variance is too small to justify unification of these two constructs. Successful self-control is supported by briskness, sensory sensitivity, and low level of emotional reactivity.

\section{KEY WORDS}

self-control; temperament; Regulative Theory of Temperament

CORRESPONDING AUthor - Prof. Edward Nęcka, Institute of Psychology, Jagiellonian University in Krakow, 6 Ingardena Str., 30-060 Kraków, Poland, e-mail: edward.necka@uj.edu.pl

AUthors' CONTRiBution - A: Study design · B: Data collection · C: Statistical analysis · D: Data interpretation .

E: Manuscript preparation · F: Literature search · G: Funds collection

TO CITE THIS ARTICLE - Nęcka, E., Korona-Golec, K., Hlawacz, T., Nowak, M., \& Gruszka-Gosiewska, A. (2019).

The relationship between self-control and temperament: a contribution to the self-control definition debate.

Current Issues in Personality Psychology, 7(1), 24-31.

RECEIVED 20.03.2018 · REVIEWED 16.01.2019 • ACCEPTED 23.01.2019 · PUBLISHED 11.02.2019 


\section{BACKGROUND}

Self-control is currently one of the most popular topics of psychological research. Its popularity is driven by the fundamental role of behavioral self-regulation in maintaining appropriate functioning in day-to-day life. Tangney, Baumeister and Boone (2004) underscore that control processes are involved in managing stress, focusing attention on specific tasks, modifying responses according to the needs, as well as planning and performing activities required to achieve longterm goals. Numerous research findings show that people high on self-control achieve better grades and have higher socio-economic status and better relationships, to name just a few benefits (e.g., Bridgett, Oddi, Laake, Murdock, \& Bachmann, 2013; Mischel, Shoda, \& Rodriguez, 1989; Moffitt et al., 2011; Tangney et al., 2004). All of this makes it vital to understand the determinants of successful self-control. Within the individual differences approach, self-control is understood as a relatively stable personal trait. It seems important to establish other individual traits that might be predictive for the trait of self-control.

Typically, scientists face the first challenge at the beginning - when defining the subject of their research. Distinguishing self-control from other important cognitive functions (such as working memory, executive control, attention, or planning) and from other areas of individual differences (such as personality, motivation, or temperament) brings many difficulties (Bridgett et al., 2013). As a result, there have been attempts to integrate self-control with related cognitive phenomena, particularly with executive functions (e.g., Bridgett et al., 2013; Kotabe \& Hoffman, 2015; Moffitt et al., 2011; Nigg, 2017). Although integration has a lot of benefits, it also brings the risk of excessive reductionism. For example, Nigg argues that executive functions (including working memory updating) overlap with effortful control to the extent that these mechanisms could be reduced to a single one. In response to this stance, Eisenberg (2017) disagrees, giving arguments that working memory is a separate construct and cannot be treated as the equivalent of self-control.

In dictionaries, the definition of self-control is usually simple and straightforward. It is typically associated with the ability to regulate emotions, desires, and behavior (Oxford Dictionaries, 2018). Such simplicity is yet to be attained in the area of the science of selfcontrol. We encounter numerous inconsistencies and overlaps in the available literature. The term 'selfcontrol' and related concepts, such as self-regulation, inhibitory control, impulse control, or executive functions, are differently defined depending on a given strand of research or even researcher, not defined at all, or used interchangeably. In addition, when defining the concept, emphasis can be put on different aspects of self-control. To give just a few examples,
Mischel (1989) in his article on children's ability to delay gratification uses the terms 'self-control' and 'selfregulation' interchangeably. Although he focuses on behavioral control in resisting temptation, he points out that attentional mechanisms might be at the root of effective gratification delay. Tangney and her coworkers (2004) consider self-control as the capacity to adapt and to produce a good fit between oneself and the environment. The authors believe that the control ability is connected with overriding the prepotent responses and changing the behavior according to the environmental conditions. Hofmann, Baumeister, Förster, and Vohs (2012) state that the self-control dilemma appears when one's long-term goal is not compatible with current temptations or desires. Moffitt and her team (2011) propose that self-control is an umbrella construct that covers lack of impulsivity, conscientiousness, self-regulation, deferment of gratification, executive functions, and willpower.

Gagne (2017) enumerates the three most common approaches to self-control in children - delay of gratification/willpower, executive functioning, and temperament - thus suggesting that temperament is a dimension of self-control. Rothbart and Derryberry (1981) propose that, from the developmental perspective, temperament consists of reactivity and self-regulation. The former amounts to increased sensitivity to both external stimulation and internal sensations from the organism, thus increasing the proneness to emotional distress. The latter refers to the processes that modulate reactivity, particularly in its emotional aspects, thus making it less harmful in situations defined by stress or frustration. The cognitive processes that constitute self-regulation in children pertain mostly to executive attention and effortful control (Rothbart \& Derryberry, 1981). Hence, effortful control and executive attention must be treated as important facets, or determinants, of self-regulation. Several other authors also point out that effortful control has a lot in common with executive attention, or executive functions (EFs) in general (Bridgett et al., 2013; Eisenberg, 2017; Nigg, 2017).

With such a variety of definitions and their components, the core of self-control remains unclear and therefore leaves a great amount of inconsistency. Such a situation makes it very difficult to define a theoretical framework for self-control research. This study is an attempt to contribute to the wider debate on definition of self-control by examining its relationship with temperament in adult healthy volunteers. Although the link between temperament and self-control has been revealed in early childhood (Rothbart \& Derryberry, 1981; Rothbart, Ellis, \& Posner, 2004; Rueda, Posner, \& Rothbart, 2011), relevant research findings with adults are rather scarce (e.g., Kwapis, 2011). We believe that revealing the relationships between temperament and self-control might help to decide whether temperamental traits should 
be regarded as defining components of the trait of self-control.

We define self-control as the ability to behave in relative autonomy from external pressures, automatisms, or impulses. This ability manifests itself in delay of gratification, inhibition of prepotent responses, emotion regulation, and adequate adaptation to a social milieu (Nęcka, 2015). Such processes require effort and are distinct from behavioral automatisms. Self-controlled behavior can be reactive or proactive - in the former case individuals simply respond to environmental stimuli, while in the latter case they plan and follow long-term goals. On the basis of our former study (Nęcka et al., 2016), we distinguish five behavioral components of self-control:

1. Goal maintenance (GM), or the ability to keep in mind one's own intentions and long-term plans;

2. Proactive control (PC), defined as the ability to create plans, prioritize goals, analyze consequences, and predict obstacles;

3. Initiative and persistence (IP), understood as the ability to set goals and take actions in order to follow one's decisions without unnecessary delays;

4. Switching and flexibility (SF), or the ability to adjust to changing circumstances and manage attention during performance of the appropriate actions;

5. Inhibition and adjournment (IA), defined as the ability to inhibit emotional reactions and refrain from immediate impulsive behavior.

Had we chosen a theory of temperament that directly incorporates self-control as a part of it, some amount of overlap would be natural. Therefore, we deliberately decided on one of the most popular modern theories of temperament that does not include self-control as one of its dimensions: the Regulative Theory of Temperament (RTT), developed by Jan Strelau (1998). The author defines temperament as a set of relatively stable personality traits, which are expressed in formal characteristics of behavior pertaining to energy and time. The energetic aspects of behavior are divided into two basic temperamental traits: emotional reactivity and activity. Emotional reactivity is a dimension that can be divided into responsiveness and persistence. People who are highly reactive are highly responsive but not very persistent, whereas people low on reactivity are more persistent but less responsive. Activity is a trait that can be defined by frequency and intensity of undertaken actions. People can modify activity and therefore regulate the level of stimulation, meeting their individual needs. As regards the temporal characteristics of behavior, there are such attributes as speed, mobility, or regularity of responses. Ultimately, Strelau (1998) points out that the final outcome of behavior is a result of the co-operation of the motor system, cognition, and emotions, and it depends on feedback loops with physiological systems (e.g., cardiovascular and endocrine systems).
In this study, we rely on the version of RTT outlined by Strelau and Zawadzki (1995, 1997), who distinguish six temperament traits:

1. Briskness - the tendency to react quickly, maintain a high pace of performance and easily switch from one behavior to another in order to adjust to environmental changes;

2. Perseverance - the tendency to continue or repeat given behavior when a stimulus is no longer present;

3. Sensory sensitivity - the tendency to react to stimuli of low intensity;

4. Emotional reactivity - the tendency to react strongly to emotional stimuli, which implies high sensitivity and low emotional resilience;

5. Endurance - the tendency to react adequately in situations that require long-term activity or intense behavior;

6. Activity - the tendency to seek highly stimulating behavioral opportunities.

Previous studies suggest that we should expect a correlation of some of the self-control dimensions and certain temperament factors. Strelau and $\mathrm{Za}-$ wadzki (1997) found a positive correlation between briskness and conscientiousness, a trait that highly and positively correlates with self-control (e.g., Nęcka, 2015; Nęcka et al., 2016). The correlation should be especially strong in the case of the switching and flexibility component of self-control. According to Ledzińska, Zajenkowski, and Stolarski (2013), briskness facilitates better cognitive functioning, especially in the case of processes connected with switching between tasks and activities (see also: Gruszka \& Owen, 2015), inhibition, and scanning of the visual field. As to perseverance, Ledzińska's team found that this trait is associated with a suboptimal level of cognitive functioning, including performance in tasks that engage the executive functions (Ledzińska et al., 2013). There is no clear evidence concerning the relationship of sensory sensitivity and self-control. However, Ledzińska and co-workers (2013) found this trait to be positively correlated with the ability to search the perceptual field. As to emotional reactivity, the results obtained by Kwapis (2011) suggest that this trait is negatively correlated with persistence in doing a relatively simple task but it may be helpful in the process of mobilization of energetic resources needed to deal with a more demanding task. The negative correlation of emotional reactivity with persistence has been demonstrated by Łukaszewski and MarszałWiśniewska (2006) as well. Muraven (2010) found that practicing self-control results in greater endurance. Activity was found to correlate negatively with performance in computerized tests of attention and memory, and positively with the cognitive control measured with questionnaires (Ledzińska et al., 2013). Proactive control that includes deliberative planning, detached from the need to respond quickly to press- 
ing environmental needs, should be mainly unrelated to temperamental traits (Bridgett et al., 2013).

We believe that the state of the art in both temperament and self-control research suggests that these areas of individual differences must have a common ground. Both temperament and self-control seem strictly related to energy and effort. On the one hand, temperament may be understood as an individually differentiated reservoir of energy that is needed to deal with demanding tasks, particularly in difficult environmental conditions (e.g., stress, time pressure, rapid changes of stimulation). On the other hand, self-control amounts to effortful control of one's own behavior in order to strive for important longdistance goals in spite of obstacles and temptations. Such effortful control needs energetic resources because, as it seems, self-control cannot be exerted automatically and effortlessly. Hence, the ability to control oneself must be somehow related to temperamental characteristics, although this relationship has not been extensively examined yet at the empirical level. Our study is an attempt to address this theoretical question with a psychometric approach.

On the basis of the above-presented theoretical frameworks and previous research, we can formulate a number of predictions concerning the relationships between the two constructs and their specific dimensions. For the self-control trait we expect: (a) a positive correlation with briskness, (b) a positive relationship with endurance, especially for the GM component, (c) a negative correlation with perseverance, especially in the case of switching as well as inhibition, and (d) a negative relationship with emotional reactivity. Taking into account the existing body of evidence, we do not expect any relationship of self-control with (a) activity and (b) sensory sensitivity. For the same reason, no relationship is expected between proactive control and temperament.

\section{PARTICIPANTS AND PROCEDURE}

\section{PARTICIPANTS}

One hundred and forty-six participants took part in the research (95 women). Their mean age was 23.84 $(S D=6.74$, range 18-66 years). All participants were native Polish speakers. The examined sample consisted of students, undergraduates, and graduates as well as business professionals. The participants were not psychology students or graduates.

\section{MATERIALS AND PROCEDURE}

Self-control. We used the NAS-50 questionnaire developed by ourselves (Nęcka et al., 2016) in order to measure trait self-control and its five components.
This tool consists of 50 items. Its internal consistency is satisfactory (Cronbach's alpha for NAS-50 total score $\alpha=.86$, for the subscales $\alpha$ between .73 and .87).

Temperament. The traits of temperament were assessed with the Formal Characteristics of Behavior Temperament Inventory (FCB-TI), developed by Strelau and Zawadzki (1995, 1997). This questionnaire also has good internal consistency indices (Cronbach's $\alpha$ between .72 and .88 , depending on the subscale).

Participants were asked to fill in a printed set of questionnaires as well as provide standard demographic data (age, gender). All research materials were in their original language (Polish). The study was anonymous. All participants gave their informed consent to take part in the study. The results were analyzed with IBM SPSS Statistics (v24) software.

\section{RESULTS}

NAS-50 overall score correlated significantly with five out of six FCB-TI subscales. Also, four out of five subscales of NAS-50 correlated with various subscales of FCB-TI. These results are shown in Table 1. As we can see, the general level of the trait of selfcontrol, expressed with NAS-50 overall scores, is predicted positively by briskness of behavior $(r=.49$, $p<.01)$, sensory sensitivity $(r=.23, p<.01)$, and endurance $(r=.37, p<.01)$. However, the dimensions of perseverance and emotional reactivity predict the trait of self-control negatively $(r=-.30, p<.01$, and $r=-.49, p<.01$, respectively). Interestingly, the temperamental dimension of activity was found to be unrelated to self-control.

Analyzing these data in detail, we can see that the briskness subscale predicted not only the overall scores of NAS-50 but also its particular subscales. Although the strongest relationship pertains to switching and flexibility $(r=.53, p<.01)$, briskness of behavior predicts goal maintenance $(r=.35, p<.01)$, initiative and persistence $(r=.32, p<.01)$, and inhibition and adjournment $(r=.21, p<.05)$ as well. Proactive control is not related to this dimension, or to other subscales of FCB-TI. Emotional reactivity is negatively correlated at the moderate level $(-.31<r<-.40, p<.01)$ with all NAS-50 subscales, except proactive control. Next, endurance predicts all subscales of NAS-50 except proactive control, and it looks particularly important for switching and flexibility $(r=.49, p<.01)$. Perseverance showed weak negative correlations with all NAS-subscales $(-.17<r<-.33, p<.05)$, except proactive control. Sensory sensitivity was found to be weakly but positively correlated only with goal maintenance $(r=.17, p<.05)$ and initiative and persistence $(r=.22, p<.01)$. Finally, although temperamental activity did not predict the general level of self-control, it was found to be important for switching and flexibility $(r=.34, p<.01)$. 
Table 1

Pearson's correlation coefficients representing relationships between dimensions of temperament (FCB-TI) and measures of self-control (NAS-50)

\begin{tabular}{llcccccc}
\hline & \multicolumn{9}{c}{ FCB-TI } \\
\cline { 3 - 7 } & & BR & PE & SS & ER & EN & AC \\
\hline \multirow{2}{*}{ NAS-50 NAS-50 overall score } & $.49^{* *}$ & $-.30^{* *}$ & $.23^{* *}$ & $-.49^{* *}$ & $.37^{* *}$ & .09 \\
& Goal maintenance & $.35^{* *}$ & $-.22^{* *}$ & $.17^{*}$ & $-.31^{* *}$ & $.21^{*}$ & -.02 \\
& Proactive control & .09 & .08 & .06 & -.04 & -.03 & .02 \\
& Initiative and persistence & $.32^{* *}$ & $-.17^{*}$ & $.22^{* *}$ & $-.35^{* *}$ & $.25^{* *}$ & .09 \\
& Inhibition and adjournment & $.21^{*}$ & $-.33^{* *}$ & .14 & $-.40^{* *}$ & $.19^{*}$ & -.16 \\
& Switching and flexibility & $.53^{* *}$ & $-.24^{* *}$ & .10 & $-.38^{* *}$ & $.49^{* *}$ & $.34^{* *}$ \\
\hline
\end{tabular}

Note. Significant correlations are marked with ${ }^{*}(p<.05,2$-tailed $)$ or $^{* *}(p<.01,2$-tailed). BR - briskness of behavior; PE - perseverance; SS - sensory sensitivity; ER - emotional reactivity; EN - endurance; AC - activity.

Table 2

Linear regression model with NAS-50 overall score as the dependent variable and FCB-TI subscales as predictors

\begin{tabular}{lccccc}
\hline & \multicolumn{2}{c}{$\begin{array}{c}\text { Unstandardized } \\
\text { coefficients }\end{array}$} & $\begin{array}{c}\text { Standardized } \\
\text { coefficients }\end{array}$ & & $p$ \\
\cline { 2 - 4 } & \multicolumn{1}{c}{$\mathrm{B}$} & Std. Error & $\beta$ & & \\
\hline (Constant) & 156.33 & 11.67 & & 13.40 & .000 \\
FCB-TI Briskness & 1.38 & 0.42 & .29 & 3.31 & .001 \\
FCB-TI Perseverance & -0.60 & 0.48 & -.11 & -1.26 & .211 \\
FCB-TI Sensory sensitivity & 0.98 & 0.40 & .18 & 2.48 & .014 \\
FCB-TI Emotional reactivity & -1.19 & 0.44 & -.27 & -2.71 & .007 \\
FCB-TI Endurance & 0.15 & 0.40 & .04 & 0.39 & .698 \\
FCB-TI Activity & -0.31 & 0.35 & -.07 & -0.89 & .277 \\
\hline
\end{tabular}

Taking into account possible mutual relationships between various temperamental dimensions, we computed partial correlation coefficients between the NAS-50 total score and six FCB-TI subscales. In this way we intended to check whether the relationships reported in Table 1 would change if the influence of possibly inter-correlated variables were controlled for. It was found that only three dimensions of temperament remained significantly correlated with self-control after controlling for all other dimensions. These were: briskness of behavior (zero order $r=.49$, partial correlation coefficient $=.27$ ), sensory sensitivity (zero order $r=.23$, partial correlation coefficient $=.21$ ), and emotional reactivity (zero order $r=-.49$, partial correlation coefficient $=-.22$ ). Since partial correlation coefficients express uncontaminated relationships between variables, we can provisionally conclude that self-controlling people are characterized by speedy adaptation to changing environmental conditions (briskness), high receptiveness to stimuli of low intensity (sensory sensitivity), and low susceptibility to emotional stimulation (low level of emotional reactivity). In order to obtain a more detailed picture concerning the relationships between temperament and self-control, we analyzed the data in the regression model. Six FCB-TI subscales entered the equation but only three of them were found to be significant predictors of the NAS-50 total score. These were the same variables that showed significant partial correlations with self-control. Altogether, they explained about one third of the NAS-50 overall score variance $\left(F\{6,139\}=13.08, p<.001, R^{2}=.36\right.$, adjusted $\left.R^{2}=.33\right)$. Table 2 shows that emotional reactivity is the strongest predictor of inefficient self-control: the increase of emotional reactivity by one standard deviation results in lessening the trait self-control by about one fourth of the standard deviation $(\beta=-.27)$. Analogically, briskness of behavior was found to be the strongest predictor of efficient self-control $(\beta=.29)$. The third statistically significant temperamental dimension, sensory sensitivity, was found to be a slightly weaker, albeit positive, predictor of self-control $(\beta=.18)$. 


\section{DISCUSSION}

The results are generally in line with our hypotheses. As expected, there are several self-control and temperament components that are related to each other. The overall results show in general that people characterized by such temperamental traits as briskness, endurance, and low level of emotional reactivity are more effective in tasks and situations that require exertion of self-control. The variance of self-control explained by temperament is small enough to exclude the possibility that temperament and self-control are substitutable constructs but large enough to justify looking for their common ground.

In line with our predictions and previous research, we have found briskness to be positively correlated with self-control and its four components: initiative and persistence (IP), switching and flexibility (SF), inhibition and adjournment (IA), and goal maintenance (GM). As a tendency to quickly react to changes (Strelau, 1998), briskness probably enables better adjustment to changing environmental conditions, which is an important component of the self-control definition (Tangney et al., 2004). We have also found endurance, a trait facilitating efficient activity in situations that require intense and long-term effort (Strelau, 1998), to be positively correlated with global score of self-control. Four self-control components showed a significant relationship with endurance: initiative and persistence (IP), switching and flexibility (SF), inhibition and adjournment (IA), and goal maintenance (GM); these results are in line with our hypotheses. The ability to act in line with long-term goals is often described as a core element in self-control definitions (e.g., Nęcka, 2015; Tangney et al., 2004). This positive relationship confirms the hypothesis that self-control requires effort because it can exhaust mental resources (Nęcka et al., 2016; Baumeister \& Tierney, 2011).

As predicted, self-control negatively correlated with perseverance, especially in reference to the following components: switching and flexibility (SF), inhibition and adjournment (IA), initiative and persistence (IP), and goal maintenance (GM). Perseverance, defined as inability to stop a reaction once it is no longer needed (Strelau, 1998), can be contrasted with effective inhibitory control and the ability to go beyond automatic reactions. It is also harmful in situations that require switching between tasks and actions. Therefore, negative relationships between perseverance and various aspects of self-control seem understandable. As to emotional reactivity, it is linked with a tendency to impulsively react to emotional stimuli (Strelau, 1998); therefore, it should not be surprising that this temperamental trait was found to be negatively related to all aspects of selfcontrol except proactive control. A high level of emotional reactivity excludes effective self-control, since the ability to regulate reactions by effortful control in response to stress and environmental stimuli is one of the vital aspects of self-regulation (Rothbart \& Derryberry, 1981).

We predicted that the temperamental trait of activity would not be related to self-control. Indeed, we found this trait to be unrelated to the general level of self-control and only weakly related to one of the self-control components, namely switching and flexibility. Activity is regarded to be one of the basic dimensions of individual differences because of its role in human regulative activity (Strelau \& Zawadzki, 2012). If the individual level of 'stimulus hunger' is high, and the environment is rather boring and predictable, activity is 'switched on' as a means to ensure inflow of stimulation. In contrast, if the individual need for stimulation is low, and the environment gets richer and richer in new or intensive stimuli, activity is 'switched off' in order to ensure a low level of excitation. This regulatory activity is at the core of the Regulative Theory of Temperament (Strelau, 1998). However, being an effective regulator of the optimal level of stimulation, activity may cause failures of self-control because of the fact that it goes in line with sensation seeking and thus increases the probability of being involved in risky situations. A high level of activity and sensation seeking may even result in various acts of social, moral, or legal transgressions. On the other hand, this trait may be helpful in situations that need effective adaptation to demanding environmental conditions, for example in stress. Altogether, activity does not support self-control, except switching and flexibility, which can be explained by the fact that the ability to easily change tasks and actions underlies the tendency to explore and seek new stimulation.

When looking at the future-oriented aspect of self-control, called proactive control (PC), it proves to be not related to temperament. Proactive control determines successful planning and prioritizing, as well as expecting potential challenges for long-term plans. An ability to plan carefully one's own actions is considered to be a fundamentally important part of effortful control (Eisenberg, Smith, \& Spinrad, 2004). Therefore, its lack of any relationships with temperamental traits seems meaningful. It looks like temperament helps to exert the reactive aspects of self-control rather than its future oriented facets. In other words, temperament seems to be a kind of 'energetic reservoir' necessary to initiate and continue actions (IP), keep in mind one's own intentions (GM), switch between tasks (SF), and exert inhibitory control (IA). However, such a 'reservoir' seems not necessary for careful planning and anticipation of possible obstacles that might jeopardize the plans (PC). We can conclude that our results justify the distinction between reactive and proactive aspects 
of self-control, since the former depend on temperament, whereas the latter do not.

Finally, let us discuss the fact that, contrary to our predictions, sensory sensitivity was found to be positively associated with self-control. Although it seems intuitive that paying attention to too many distractors of low intensity would make it more difficult to concentrate on the task and maintain a current goal, our results show something different. People with higher sensory sensitivity were found to be better in self-control, especially in initiative and persistence (IP) and goal maintenance (GM). A possible explanation here is that high sensitivity may actually help people in identification of possible distractors and therefore in tackling them more effectively and quickly, which in the end might help in maintaining and pursuing a goal in the long term. Further research is needed to explore the relationship between these two constructs.

Going back to the self-control definition debate, our results suggest that temperament should not be included in the realm of self-control as one of its components. Temperamental resources seem to be necessary for exertion of efficient self-control; therefore, some amount of common variance is predictable. However, the relationships we found are weak enough to justify radical decisions, such as inclusion of temperamental traits in the definition of self-control.

\section{CONCLUSIONS}

There are a number of self-control and temperament components that significantly correlate with each other. Although the proportion of self-control variance explained by temperament is moderate (33\%), it is clear that there are certain overlapping areas. Interestingly, only the reactive aspects of self-control depend on temperament, the proactive ones not being related. Moreover, the trait of activity, which is regarded as fundamentally important for temperament, was found to be unrelated to the general index of self-control and majority of its components, except switching and flexibility. It seems that activity may have both a positive and a negative influence on the efficacy of self-control, and therefore the correlation coefficients turned out to be mostly insignificant. In general, effective self-control is predicted by a high level of briskness and sensory sensitivity, and a low level of emotional reactivity. From the applied psychology point of view, it may be advisable to look after people whose constellation of temperamental traits - low level of briskness and sensory sensitivity but increased emotional reactivity - predicts deficient self-control. Such people may need assistance in the process of personal development toward successful self-regulation of behavior.

\section{ACKNOWLEDGMENTS}

The study was financed by the National Science Centre in Poland $(\mathrm{NCN})$ on the basis of decision number DEC-2013/08/A/HS6/00045.

\section{References}

Baumeister, R. F., \& Tierney, J. (2011). Willpower: rediscovering the greatest human strength. New York, NY: Penguin.

Bridgett, D. J., Oddi, K. B., Laake, L. M., Murdock, K. W., \& Bachmann, M. N. (2013). Integrating and differentiating aspects of self-regulation: Effortful control, executive functioning, and links to negative affectivity. Emotion, 13, 47-63. doi: 10.1037/a0029536

Eisenberg, N. (2017). Commentary: What's in a word (or words) on the relations among self-regulation, self-control, executive functioning, effortful control, cognitive control, impulsivity, risk-taking, and inhibition for developmental psychopathology reflections on Nigg (2017). Journal of Child Psychology and Psychiatry and Allied Disciplines, 58, 384-386. doi: 10.1111/jcpp. 12707

Eisenberg, N., Smith, C. L., \& Spinrad, T. L. (2004). Effortful control: Relations with emotion regulation, adjustment, and socialization in childhood. In F. Baumeister \& K. D. Vohs (Eds.), Handbook of self-regulation: Research, theory, and applications (pp. 263-283). New York, NY: Guilford Press.

Gagne, J. R. (2017). Self-control in childhood: A synthesis of perspectives and focus on early development. Child Development Perspectives, 11, 127-132. doi: 10.1111/cdep. 12223

Gruszka, A., \& Owen, A. (2015). Temperamental variation in learned irrelevance in humans. Current Issues in Personality Psychology, 3, 94-104.

Hofmann, W., Baumeister, R. F., Förster, G., \& Vohs, K. D. (2012). Everyday temptations: An experience sampling study of desire, conflict, and self-control. Journal of Personality and Social Psychology, 102, 1318. doi: 10.1037/a0026545

Kotabe, H. P., \& Hofmann, W. (2015). On integrating the components of self-control. Perspectives on Psychological Science, 10, 618-638. doi: 10.1177/ 1745691615593382

Kwapis, K. (2011). Temperamentalna regulacja zasobów energetycznych w zadaniach wymagających samokontroli [Temperamental regulation of energetic resources in tasks requiring self-control]. Studia Psychologiczne, 49, 23-37. doi: 10.2478/v10167010-0033-9

Ledzińska, M., Zajenkowski, M., \& Stolarski, M. (2013). Temperament i poznanie. Energetyczne i czasowe zaplecze umystu [Temperament and cognition. Energy and temporal supplies of the mind]. Warszawa: Wydawnictwo Naukowe Scholar. 
Łukaszewski, W., \& Marszał-Wiśniewska, M. (2006). Wytrwałość w działaniu: Wyznaczniki sytuacyjne i osobowościowe [Persistence in action. Situational and personality determinants]. Gdańsk: Gdańskie Wydawnictwo Psychologiczne.

Mischel, W., Shoda, Y., \& Rodriguez, M. I. (1989). Delay of gratification in children. Science, New Series, 244, 933-938. doi: 10.1126/science.2658056

Moffitt, T. E., Arseneault, L., Belsky, D., Dickson, N., Hancox, R. J., Harrington, H., Houts, R., Poulton, R., Roberts, B., Ross, S., Sears, M., Thomson, W., \& Caspi, A. (2011). A gradient of childhood self-control predicts health, wealth, and public safety. Proceedings of the National Academy of Sciences of the United States of America, 108, 2693-2698. doi:10.1073/ pnas. 1010076108

Muraven, M. (2010). Building self-control strength: practicing self-control leads to improved self-control performance. Journal of Experimental Social Psychology, 46, 465-468. doi: 10.1016/j.jesp.2009.12.011

Nęcka, E. (2015). Self-Control Scale AS-36: Construction and validation study. Polish Psychological Bulletin, 46, 488-497. doi: 10.1515/ppb-2015-0055

Nęcka, E., Wujcik, R., Orzechowski, J., Gruszka, A., Janik, B., Nowak, M., \& Wójcik, N. (2016). NAS-50 and NAS-40: New scales for the assessment of selfcontrol. Polish Psychological Bulletin, 47, 346-355. doi: 10.1515/ppb-2016-0041

Nigg, J. T. (2017). Annual Research Review: On the relations among self-regulation, self-control, executive functioning, effortful control, cognitive control, impulsivity, risk-taking, and inhibition for developmental psychopathology. Journal of Child Psychology and Psychiatry and Allied Disciplines, 58, 361-383. doi: /10.1111/jcpp. 12675

Oxford Dictionaries (2018). Definition of'self-control' in US English. Oxford: Oxford University Press. Retrieved from https://en.oxforddictionaries.com/ definition/us/self-control

Rothbart, M. K., \& Derryberry, D. (1981). Development of individual differences in temperament. In M. E. Lamb \& A. L. Brown (Eds.), Advances in Developmental Psychology (Vol. 1, pp. 37-86). Hillsdale, NJ: Erlbaum.

Rothbart, M. K., Ellis, L. K., \& Posner, M. I. (2004). Temperament and self-regulation. In R. F. Baumeister \& K. D. Vohs (Eds.), Handbook of self-regulation research: research, theory, and applications. (pp. 357-370). New York: Guilford Press.

Rueda, M. R., Posner, M. I., \& Rothbart, M. K. (2011). Attentional control and self-regulation. In R. F. Baumeister \& K. D. Vohs (Eds.), Handbook of self-regulation: Research, theory, and applications ( $2^{\text {nd }}$ ed., pp. 284-299). New York, NY: Guilford Press.

Strelau, J. (1998). Temperament: A psychological perspective. New York, NY: Plenum Press.

Strelau, J., \& Zawadzki, B. (1995). The Formal Characteristics of Behavior - Temperament Inventory
(FCB-TI): Validity studies. European Journal of Personality, 9, 207-229.

Strelau, J., \& Zawadzki, B. (1997). Formalna charakterystyka zachowania - Kwestionariusz Temperamentu (FCB-TI) [Formal Characteristics of Behaviour - Temperament Inventory (FCB-TI)]. Warszawa: Pracowania Testów Psychologicznych PTP.

Strelau, J., \& Zawadzki, B. (2012). Activity as a temperament trait. In M. Zentner \& R. L. Shiner (Eds.), Handbook of Temperament (pp. 83-104). New York: Guilford Press.

Tangney, J. P., Baumeister, R. F., \& Boone, A. L. (2004). High self-control predicts good adjustment, less pathology, better grades, and interpersonal success. Journal of Personality, 72, 271-324. doi: 10.1111/j.0022-3506.2004.00263.x 